\title{
THE EFFECTS OF ROTARY DEGASSING TREATMENTS ON THE MELT QUALITY OF AN AI-Si CASTING ALLOY
}

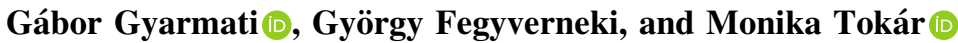 \\ Foundry Institute, University of Miskolc, Miskolc-Egyetemváros 3515, Hungary
}

Tamás Mende (1)

Institute of Physical Metallurgy, Metalforming and Nanotechnology, University of Miskolc, Miskolc-Egyetemváros 3515, Hungary

Copyright (C) 2020 The Author(s)

https://doi.org/10.1007/s40962-020-00428-z

\begin{abstract}
In order to produce cast components, which meet the quality requirements of the automotive and aerospace industries, the control of liquid metal quality prior to the casting process is essential. Rotary degassing is the most commonly used melt treatment method in the foundry industry, which can effectively reduce the inclusion and solute hydrogen content of the metal. This procedure is often combined with fluxing, which allows more efficient inclusion removal during melt processing. In this study, the effects of rotary degassing treatments executed with and without flux addition on the melt cleanliness were com-

the fracture surfaces of K-mold samples were analyzed with energy-dispersive $X$-ray spectroscopy. Based on the results, rotary degassing coupled with flux addition can be an effective inclusion and solute hydrogen removal technique that can significantly improve melt quality. On the other hand, rotary degassing executed without flux addition can increase the inclusion content of the melts. This can be attributed to the chemical reaction between the liquid alloy and the $\mathrm{N}_{2}$ purging gas during the degassing process. It was also found that inclusion content highly influences the tendency to porosity formation.
\end{abstract} pared. The quality of the molten metal was characterized by the microscopic inspection of $K$-mold specimens, $X$-ray computed tomography of reduced pressure test samples, and by Density-Index evaluation. The inclusions found on
Keywords: aluminum alloy, metal quality, degassing, fluxing, computed tomography, bifilm

\section{Introduction}

Regardless of the casting process used during the manufacture of cast components, in order to ensure adequate mechanical properties and avoid defects like inclusions, porosity, and leakage, appropriate liquid metal quality is essential. Besides the concentration of alloying and metallic impurity elements, the number of inclusions and the solute hydrogen content are generally controlled in the common foundry practice. ${ }^{1-3}$

Inclusions are discontinuities of the material which are non-metallic or sometimes intermetallic phases embedded in a metallic matrix. ${ }^{4}$ Inclusions can occur in the form of solid particles, films or liquid droplets in the molten alloys. Usually, inclusions are non-metallic compounds like oxides, nitrides, carbides, and borides. ${ }^{5,6}$ The most common and, in fact, the most deleterious inclusions are the socalled double oxide films or bifilms, which have a significant impact on the structure and properties of cast alloys. $^{7-11}$ The formation of these defects during the liquid metal handling and processing of aluminum alloys is mostly inevitable, as any disturbance of the melt surface can cause the entrainment of the surface oxide layer. Hence, copious amounts of bifilms are introduced to the melts during typical foundry activities like melting, alloying, fluxing and pouring. ${ }^{12}$ Bifilms have a central, unbounded interface; thus, these defects act like cracks in the microstructure of the solidified casting causing significantly lowered tensile strength, elongation and fatigue life. ${ }^{13-21}$ Besides that, bifilms can easily open up and inflate into pores because of the hydrogen diffusion into 
Table 1. Chemical Composition of the Studied Aluminum Alloy (wt\%)

\begin{tabular}{lllllll}
\hline $\mathrm{Si}$ & $\mathrm{Fe}$ & $\mathrm{Cu}$ & $\mathrm{Mn}$ & $\mathrm{Mg}$ & $\mathrm{Ti}$ & $\mathrm{Sr}$ \\
\hline $6.5-7.5$ & $<0.2$ & $0.45-0.58$ & $<0.1$ & $0.36-0.45$ & $<0.2$ & $0.017-0.030$ \\
\hline
\end{tabular}

their inner gas atmosphere and the local pressure drop in the mushy zone caused by the shrinkage during solidification. ${ }^{7,8,22-26}$ These negative effects highlight the importance of good liquid metal quality control via efficient melt treatments, which aim the reduction in inclusion (especially bifilm) and solute hydrogen content of the molten alloys.

Rotary degassing is one of the most commonly used melt treatment methods in the foundry industry. During this process, $\mathrm{Ar}$ or $\mathrm{N}_{2}$ gas is injected into the melt through a rotating impeller, which provides evenly distributed, smallsized gas bubbles. These bubbles can effectively collect solute hydrogen and entrained inclusions from the liquid metal. Rotary degassing is often combined with flux addition which can highly increase the inclusion removal efficiency of the treatment. ${ }^{3,27-30}$ On the other hand, optimal technological parameters are crucial in order to improve the melt quality. The effectiveness of inclusion removal is heavily affected by treatment parameters like rotor rotational speed, rotor geometry, purging gas flow rate, treatment time and melt temperature. ${ }^{31-39}$

Rotary degassing treatments, however, could have a negative effect on the bifilm content of the liquid alloys. ${ }^{40,41}$ According to Campbell, ${ }^{7,30,42}$ even sources of high-purity inert gas contain enough trace oxygen to form a thin oxide layer inside the gas bubbles. Despite commonly referred to as an inert gas, $\mathrm{N}_{2}$ is highly reactive at temperatures above $700{ }^{\circ} \mathrm{C}$ and forms AlN with the molten aluminum. If the alloy contains $\mathrm{Mg}$, the formation of $\mathrm{Mg}_{3} \mathrm{~N}_{2}$ is also probable. ${ }^{43}$ In fact, $\mathrm{N}_{2}$ gas can be utilized in the synthesis of AlAlN composites, ${ }^{44-46}$ thus the general assumption, that $\mathrm{N}_{2}$ is an inert purging gas is not well supported. The purging gas bubbles with their nitride or oxide inner surface act as bifilm inclusions in the melt if they are not fully removed during the treatment.

Despite the fact that rotary degassing is one of the most widely used melt treatment methods in the foundry industry, the available information about the possible side effects of its application is rather limited. Therefore, the aim of this work is to fill this gap of knowledge through the investigation of the effects of rotary degassing treatments on the melt cleanliness of an aluminum casting alloy.

\section{Materials and Experimental Procedure}

\section{Melt Processing}

During the experiments, rotary degassing melt treatments were executed on an $\mathrm{Al}-\mathrm{Si}-\mathrm{Mg}-\mathrm{Cu}$ casting alloy (EN AC45500) with the application of $\mathrm{N}_{2}$ as purging gas. The concentration ranges of alloying elements of the alloy can be seen in Table 1 .

The metal was melted in a stack smelter and then transported to a resistance heated holding furnace where the melt treatments were executed. In three treatment cycles, $400 \mathrm{~g}$ of a commercially available granular flux was added to the melt following the vortex formation initiated by the rotating impeller. The chemical composition of the flux was previously investigated with $\mathrm{X}$-ray powder diffraction measurements, which identified $\mathrm{NaCl}, \mathrm{KCl}, \mathrm{Na}_{2} \mathrm{SO}_{4}$, and $\mathrm{CaF}_{2}$ as main constituents. In an additional three cycles, the rotary degassing treatments were performed without the application of the flux. During these cycles, the vortex formation stage of the treatments was omitted. The quantity of processed metal in one cycle was approximately $1000 \mathrm{~kg}$. The $\mathrm{N}_{2}$ gas flow rate was $20 \mathrm{~L} / \mathrm{min}$; the rotor revolution was $500 \mathrm{rpm}$ during vortex formation and $250 \mathrm{rpm}$ in the degassing phase of the treatment. The processing time was $12 \mathrm{~min}$ in each case. The melt temperature in the holding furnace was maintained between 740 and $750{ }^{\circ} \mathrm{C}$. Figure 1 shows photographs taken at the beginning and in the last minute of the rotary degassing treatments. As can be seen in Figure 1a, the application of the flux resulted in the formation of black, powdery dross, while during the treatments realized without flux addition (Figure 1b), a thick metallic dross layer formed on the melt surface.

\section{Melt Quality Assessment}

The changes in melt quality were characterized by the microscopic inspection of $K$-mold specimens, X-ray computed tomography (CT) of reduced pressure test (RPT) samples and Density-Index (DI) evaluation. With the aid of $K$-mold samples, the inclusion content of the melt can be quantified. The $K$-mold specimen itself is a flat bar that has four notches which act as fracture points. For the casting of the samples, the so-called $K$-mold was used, which was preheated to $200{ }^{\circ} \mathrm{C}$ prior to casting. The fracture surfaces of the specimens were inspected with a Zeiss Stemi 2000-C stereomicroscope at a magnification of $25 \times$. Based on the number of inclusions found on the fracture surfaces, a $\mathrm{K}$ - 
(a)
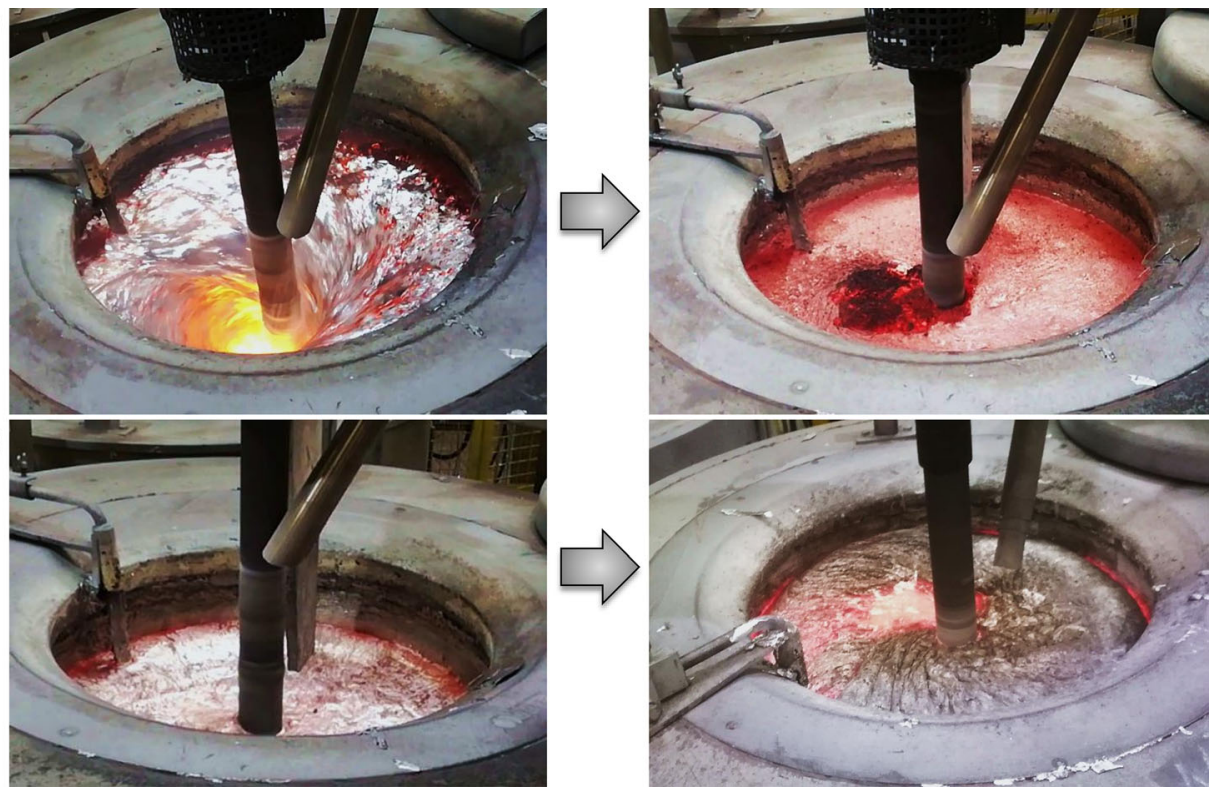

(b)

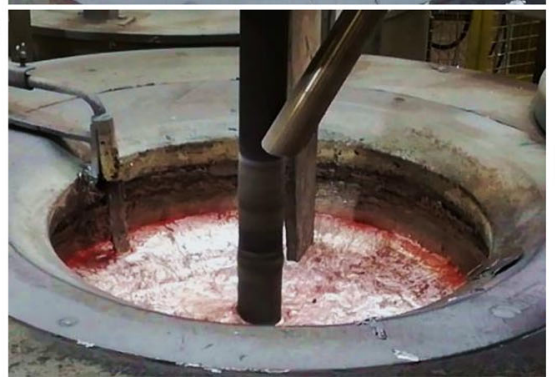

Figure 1. Melt treatments executed (a) with and (b) without flux addition.

value was determined (Eqn. 1) for each sample, which was used for the quantitative characterization of the melt purity.

$K=\frac{S}{n}$

Eqn. 1

where $K$ is the $K$-mold value (dimensionless number), $n$ is the number of examined fracture surfaces, and $S$ is the total number of inclusions found in $n$ pieces. ${ }^{47}$ Besides inclusions, the number of pores was also evaluated for each sample. The surface of the found inclusions and pores was investigated with a Zeiss EVO MA 10 scanning electron microscope (SEM) equipped with an energydispersive X-ray spectroscopy (EDS) system. During each melt preparation, $K$-mold and RPT specimens were cast three times; the number of $K$-mold samples cast at once was 5. In each case, the first pieces were prepared from the melt in the transport ladle. After the melt was poured into the holding furnace and the produced wet dross was removed, another series of $K$-mold samples were prepared. The third series of specimens were cast after melt treatment and skimming.

The RPT samples were cast into steel cups preheated to $200{ }^{\circ} \mathrm{C}$ before and following the melt treatments. The pressure of the vacuum chamber of the RPT machine was $80 \mathrm{mbar}$, in which the RPT specimens stayed for $6 \mathrm{~min}$. At each sampling step, an additional test piece was cast, which was allowed to solidify at atmospheric pressure. The density of the samples was measured using the Archimedes principle; then Density-Index was calculated according to Eqn. 2:

$\mathrm{DI}=\frac{\rho_{\mathrm{atm}}-\rho_{80 \mathrm{mbar}}}{\rho_{\mathrm{atm}}}$

Eqn. 2

where DI is the Density-Index (\%); $\rho_{\text {atm }}$ and $\rho_{80 \text { mbar }}$ are the densities of the specimens $\left(\mathrm{g} \mathrm{cm}^{-3}\right)$ solidified at atmospheric and 80 mbar pressure.

Density-Index evaluation is widely used in the foundries for the characterization of the susceptibility to the formation of porosity. ${ }^{48}$ However, RPT can be used for the characterization of the quantity of entrained bifilms present in the liquid metal. ${ }^{49,50}$ During solidification under reduced pressure, the gas phase trapped between the oxide layers of double oxide films is expanded. Furthermore, the solubility of hydrogen in the alloy is lowered due to the reduced hydrogen partial pressure. In this way, the $\mathrm{H}_{2}$ precipitation process inside the bifilms and the growth of the created pores is accelerated. ${ }^{51,52}$ This allows us the quantitative characterization of bifilm quantity based on the number and size of pores found in the RPT samples. The detection of pores can be realized using nondestructive characterization techniques like X-ray computed tomography (CT), which was used in this study for the porosity analysis of RPT specimens. This technique is a relatively new melt quality assessment method, for which a detailed description is given in Ref. 8. The CT scanning of the test pieces was realized with a GE Seifert X-Cube Compact $225 \mathrm{kV}$ apparatus with an acceleration voltage of $135 \mathrm{kV}$, and a tube current of $0.8 \mathrm{~mA} .900$ images were acquired during on rotation of the specimens. VGSTUDIO MAX 3.2 software was used for image reconstruction and processing. The segmentation of pores was conducted with the VGDefX algorithm, which is a part of the porosity analysis module of the software. For each pore, a probability value was evaluated by the software, which depends on the local contrast of voxels. Objects with a volume smaller than $0.05 \mathrm{~mm}^{3}$ and pores with a probability value lower than 0.9 were ignored. Based on the data acquired during the CT analysis, pore number density and pore volume fraction were calculated for the samples cast before and following 
the melt treatments. These parameters were used for the quality evaluation of the molten alloy.

\section{Results and Discussion}

\section{K-mold Samples}

The results of $K$-mold fracture analysis are shown in Figure 2. Based on the average $K$-values (Figure 2a) of melts in the transport ladle and in the holding furnace before treatment, the melt quality is significantly damaged during the pouring into the holding furnace, which is most probably due to the turbulent entrainment of the surface oxide layer caused by the high (ca. $1.5 \mathrm{~m}$ ) melt falling height. However, the most significant increment in inclusion content was evaluated in the case of melts treated without flux addition. Contrary to the flux-treated melts, where the average $K$-value was reduced by approximately $60 \%$, the inclusion content was doubled during rotary degassing performed without fluxing. It is an extraordinary result, as rotary degassing treatments are intended to remove both solute hydrogen and inclusions from the melt, but in this case, the number of inclusions had increased during degassing, which indicates that the melt quality was seriously damaged during the treatments.

As can be seen in Figure 2b, before melt treatments, the fracture surfaces of $K$-mold samples contained a large number of pores, which was significantly reduced due to the melt processing. However, in the case of degassing
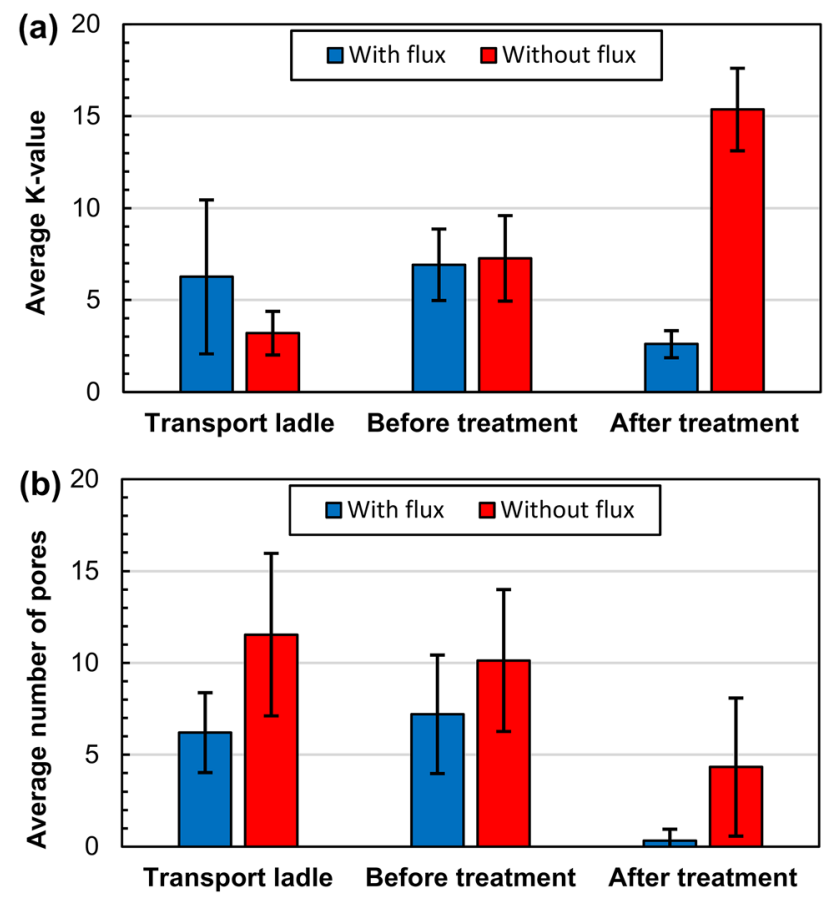

Figure 2. (a) Average K-values and (b) the average number of pores found on the fracture surface of $\mathrm{K}$ mold samples. executed without flux addition, the degree of porosity was relatively high even after treatments. Figure 3 shows some examples of inclusions and a pore found on the fracture surfaces of $K$-mold samples. In the majority of cases, filmlike inclusions could be observed. As it is showcased by the example in Figure 4, the two distinct layers of these defects could be distinguished on the opposing fracture surfaces, which indicate that these inclusions are bifilms.

As it was highlighted above, in the case of treatments conducted without fluxing, the number of inclusions had increased significantly. The samples cast from these degassed melts had a large number of small-sized (0.05-0.1 $\mathrm{mm}$ in largest diameter) inclusions (Figure 5). These small inclusions could be only observed after melt treatments, which indicates that these defects were created during the degassing process. On the other hand, when flux was applied, there were only a few of these tiny films on the fracture surfaces, which suggests that the flux treatment efficiently removed most of them.

Figure 6 shows the results of EDS-SEM analysis of the surface of three, film-like inclusions found on the fracture surfaces of $K$-mold specimens. The inclusion in Figure $6 \mathrm{a}$ was found in a sample cast before melt treatments, as the other two (Figure 6b and c) were observed in samples taken after degassing treatments. Based on its $\mathrm{O}$ and $\mathrm{Mg}$ content, the wrinkled film shown in Figure 6a is probably a thin spinel $\left(\mathrm{MgO} \cdot \mathrm{Al}_{2} \mathrm{O}_{3}\right)$ film, as the alloy contains less $\mathrm{Mg}$ than $2 \mathrm{wt} \%$, but significantly more than $0.005 \mathrm{wt} \%$, the formation of spinel is more feasible than that of $\mathrm{Al}_{2} \mathrm{O}_{3}$ or $\mathrm{MgO} .{ }^{53}$ The inclusions in Figure $6 \mathrm{~b}$ and contain a significant amount of $\mathrm{N}$, which suggests that these are mixed nitride-oxide films. The defect in Figure 6c appears to be a thicker, i.e., "old" nitride-oxide film, which has a layered plate-like structure. As the inclusions found after melt treatments contained a significant amount of $\mathrm{N}$, and the degassing treatments resulted in an increased inclusion content, it is possible that these defects were the results of the interaction between the $\mathrm{N}_{2}$ purging gas and the liquid alloy.

The inner surface of pores found in $K$-mold samples was also investigated with SEM. It was found that vanishingly thin, wrinkled oxide films cover the surface of the dendrites of the alloy (see Figure 7). This indicates that the pores were formed due to the presence of oxide films, which explains the relatively high amount of porosity which was observed in the case of melts treated without flux addition, where the inclusion content was exceptionally high after degassing. The presence of these pores could be explained by the mechanism supposed by Campbell, ${ }^{54}$ which is illustrated in Figure 8. During the solidification of the alloy, bifilms can act as barriers against the flow of the interdendritic liquid, especially in the thin section of the $K$ mold samples, where the liquid flow is already restricted by the reduced cross section. The central unbounded interface 

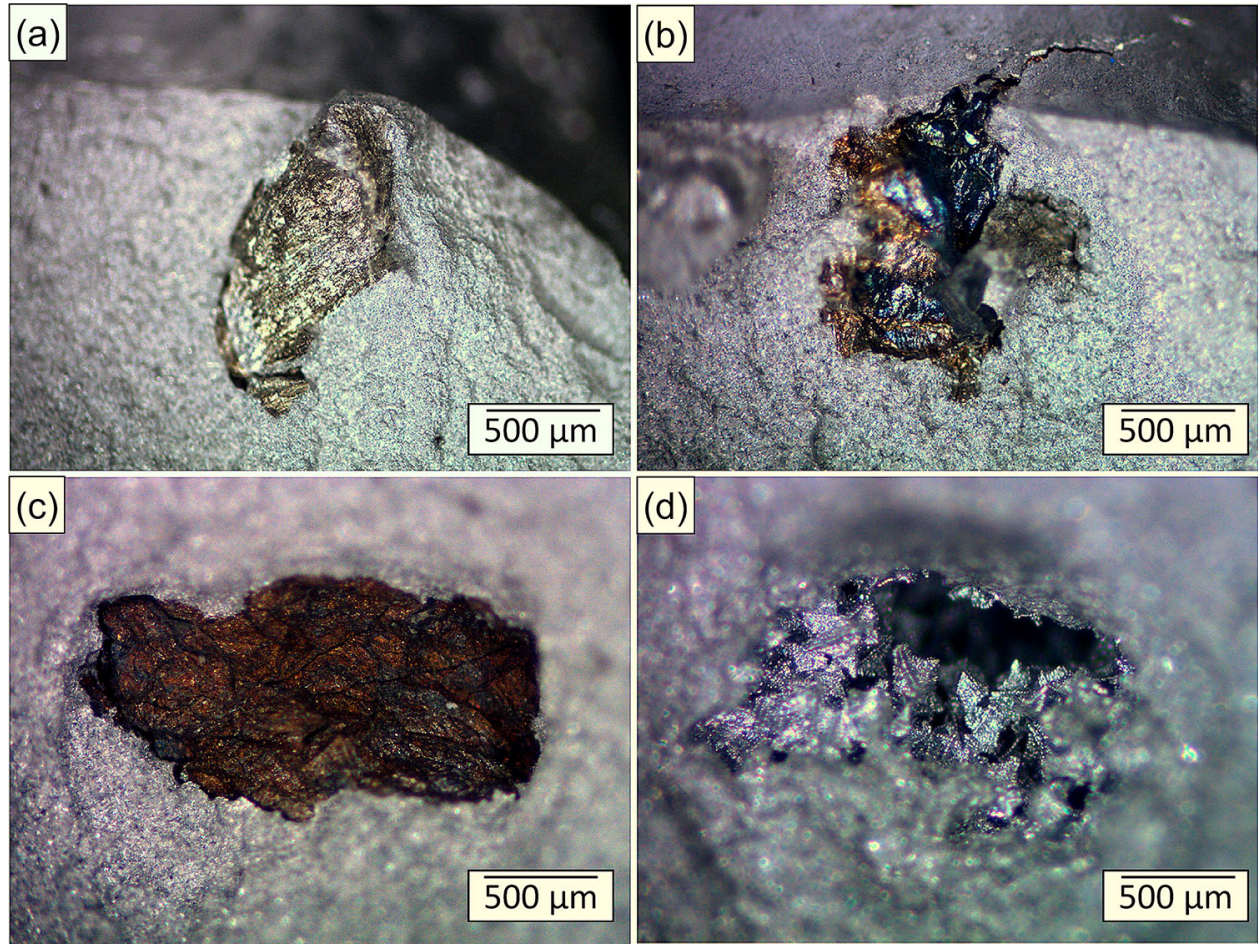

Figure 3. (a-c) Variety of film-like inclusions and (d) an example of a pore found on the fracture surfaces of K-mold samples.
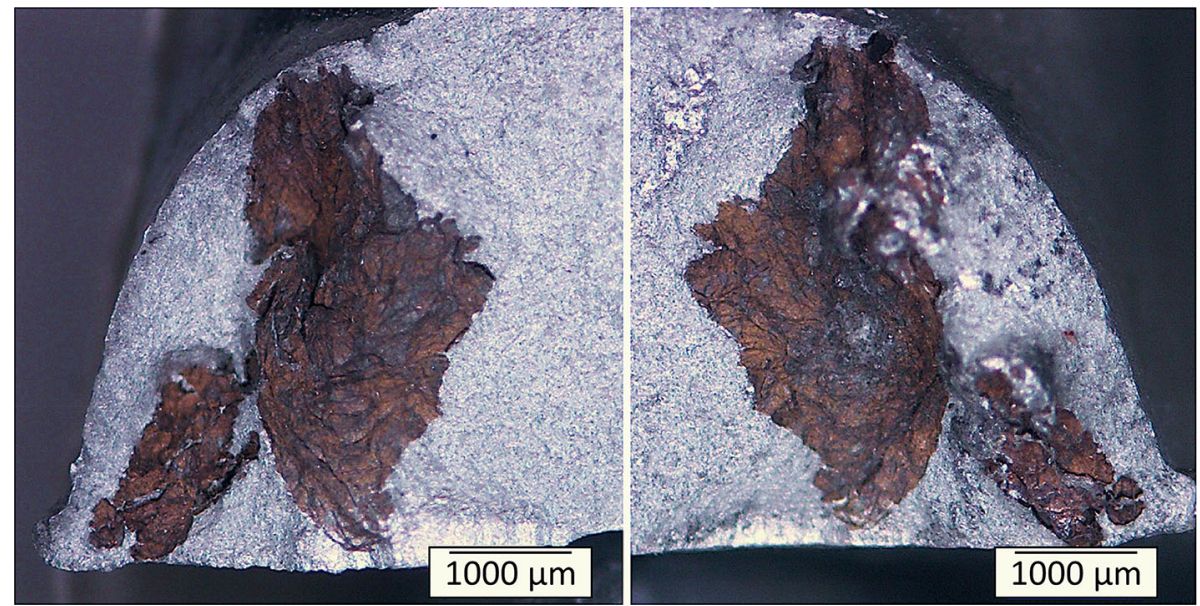

Figure 4. Two halves of the same bifilm defect found on opposing fracture surfaces.

of the bifilm defect can be decohered due to hydrostatic tension, which results in the opening and inflation of the defect which leads to the formation of a shrinkage cavity.

\section{Reduced Pressure Test}

The results of Density-Index evaluation are presented in Figure 9. The average Density-Index values were significantly lowered due to the melt treatments in each case, which suggests that the degassing treatments were efficient regarding solute hydrogen removal. Based on the results, the DI values belonging to the melts in the transport ladle were significantly higher than the results evaluated before treatment. This is an interesting result as the melt transfer includes pouring into the holding furnace which process should result in a significant amount of air being entrapped into the melt. This could be explained by the fact that the melt was poured onto a lesser quantity of previously degassed melt (ca. $200 \mathrm{~kg}$ ) which remained in the holding furnace from the previous cycle. Besides that, the wet dross produced during the pouring process, which contained a significant amount of the entrained air, was removed in each case. In this way, the total gas content (solute 


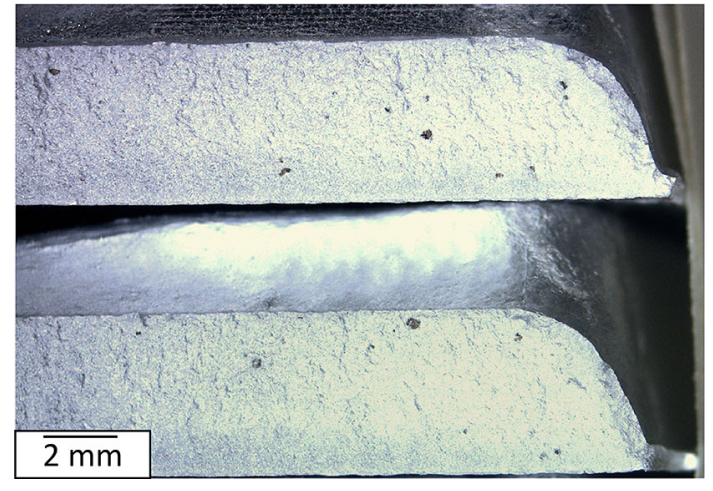

Figure 5. Small-sized inclusions in K-mold samples cast from a melt treated without flux.

hydrogen and entrained air) was less after the pouring process, which resulted in lower DI values.

Figure 10 presents the average pore number density (Figure 10a) and pore volume fraction (Figure 10b) values evaluated from the data acquired during the CT-analysis of RPT specimens. Figure 10c and d shows examples of the reconstructed images of the RPT specimens cast before and following the melt treatments. As can be seen, the RPT samples cast previously to melt processing had evenly distributed relatively large-sized pores, while the specimens cast after the treatments had one central, large-sized pore and a great number of small-sized pores throughout the volume of the test piece. As it is shown in Figure 10a, the pore number density results were lower after the melt treatments, which indicate that the number of bifilms was reduced during the treatments. From this point of view, the treatments conducted with flux addition were more efficient in reducing the pore number density; thus, the results suggest that lower bifilm content can be achieved with the aid of fluxing. However, the increment of bifilm content due to the degassing treatments, which was indicated by the higher average $K$-values (Figure 2a), was not traceable by the CT-analysis. This suggests that there were numerous small-sized bifilms in the samples which could not expand to the degree, at which they could be detected during the CT-analysis. This is mostly due to the low solute hydrogen content of the alloy, which is implied by the low DI (Figure 9) and pore volume fraction values (Figure 10b).

\section{The Formation Mechanism of Inclusions During Rotary Degassing}

According to the average $K$-values, the number of inclusions had significantly increased during degassing when flux was not applied, which indicates that the melt quality was seriously damaged during the treatments. This leads to a question that is of critical importance: how does a melt treatment method which is widely used throughout the industry can cause increased inclusion content and so worse melt quality? According to Mostafaei et al., ${ }^{32}$ rotary degassing is only effective regarding inclusion removal if optimal technological parameters are used. The application of non-ideal parameters can lead to increased inclusion content. Campbell ${ }^{7}$ highlighted that rotary degassing treatments are only effective in reducing the solute hydrogen content and removing larger oxide films from aluminum alloy melts. However, the quantity of smaller inclusions can be increased during treatments. The size of removable inclusions is highly dependent on the size of purging gas bubbles created during the treatments. Larger bubbles displace large volumes of melt during their rise to the surface, and the resultant melt flow can displace inclusions from the bubbles, preventing the contact between them. Based on the described phenomenon, the size of the smallest removable inclusion is about the same size as the inert gas bubbles used during the treatments. Because the smallest bubbles are mostly measured in millimeters, independent inclusions smaller than $1 \mathrm{~mm}$ cannot be removed from the melt by this method. ${ }^{7}$

The EDS analysis of the inclusions suggests that the majority of the found defects are mixed nitride-oxide films. To understand the formation mechanism of these films, the thermodynamic stability of different oxides and nitrides of elements of the alloy which are prone to oxidation and nitridation must be evaluated, which can be done by the comparison of the standard Gibbs free energy of formation of these compounds at different temperatures (Figure 11). The free energy plots in Figure 11 were calculated with the aid of the reference data in Ref. 55. Based on the plots, it can be ascertained that $\mathrm{Al}$ and $\mathrm{Mg}$ can be more easily oxidized than to be nitrided, and $\mathrm{MgO}$ is thermodynamically more stable than $\mathrm{Al}_{2} \mathrm{O}_{3}$. On the other hand, $\mathrm{AlN}$ could be more easily formed than $\mathrm{Mg}_{3} \mathrm{~N}_{2}$.

As it was highlighted above, when $\mathrm{N}_{2}$ is used as a purging gas, the nitridation of the liquid alloy/gas bubble interface is expected, and as AIN is thermodynamically more stable than $\mathrm{Mg}_{3} \mathrm{~N}_{2}$, a thin AlN film will form. On the other hand, even sources of high-purity $\mathrm{N}_{2}$ contain a small amount of $\mathrm{O}_{2}$ as an impurity. Besides that, graphite rotors and their shafts can absorb a considerable amount of water vapor from the atmosphere and the gas lines can be contaminated too. $7,30,42$ The consequence of this is that the purging gas bubbles can contain $\mathrm{O}_{2}$ gas and $\mathrm{H}_{2} \mathrm{O}$ vapor besides $\mathrm{N}_{2}$, and as oxides are more easily formed, than nitrides (Figure 11), oxides will form on the bubble surface until all the $\mathrm{O}_{2}$ gas and $\mathrm{H}_{2} \mathrm{O}$ vapor are consumed. After that, $\mathrm{N}_{2}$ will start to react with the liquid alloy, which leads to the nitridation of the already oxidized interface, which will lead to the formation of a mixed oxidenitride film, like the ones presented in Figure 6. Nevertheless, besides the formation of these inclusions, it must be also clarified that how it is possible that these films are present in the melt even after the melt treatments are finished.

In order to efficiently remove solute hydrogen, on arrival at the top surface of the melt, the rising $\mathrm{N}_{2}$ purging gas 

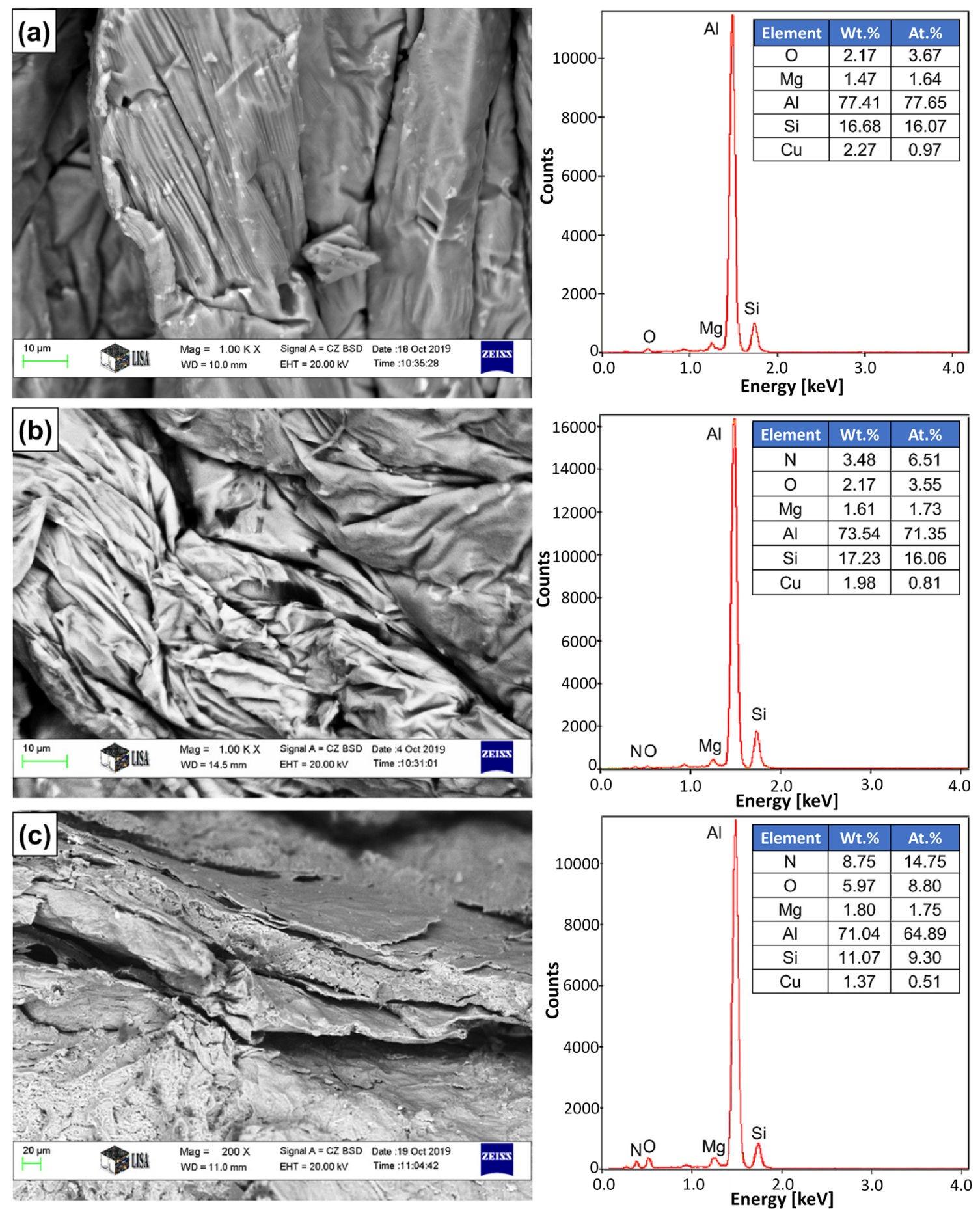

Figure 6. SEM images of the inclusions found in K-mold specimens and the results of EDS analysis of their surfaces.

bubbles should have enough buoyancy to penetrate the surface oxide layer of the melt. Besides that, their own nitride layer should be opened up to let the inner gas escape into the atmosphere. This condition is, however, highly dependent on the properties of the dross layer created during the degassing process. Martin et al., ${ }^{56}$ reported that if $\mathrm{N}_{2}$ is used for degassing, the continuous AlN formation leads to the development of a thick "wet" dross layer (i.e., dross with high metal content) on the melt surface, which phenomenon could be also observed during our experiments, as it is shown in Figure 1b. It is evident that the purging gas bubbles could not penetrate through this thick, solid dross layer and in this way, numerous $\mathrm{N}_{2}$ bubbles were being trapped under the melt surface. Raiszadeh and Griffiths ${ }^{57}$ found that the inner $\mathrm{O}_{2}$ and $\mathrm{N}_{2}$ gas of an air bubble trapped in an aluminum melt were consumed by the 


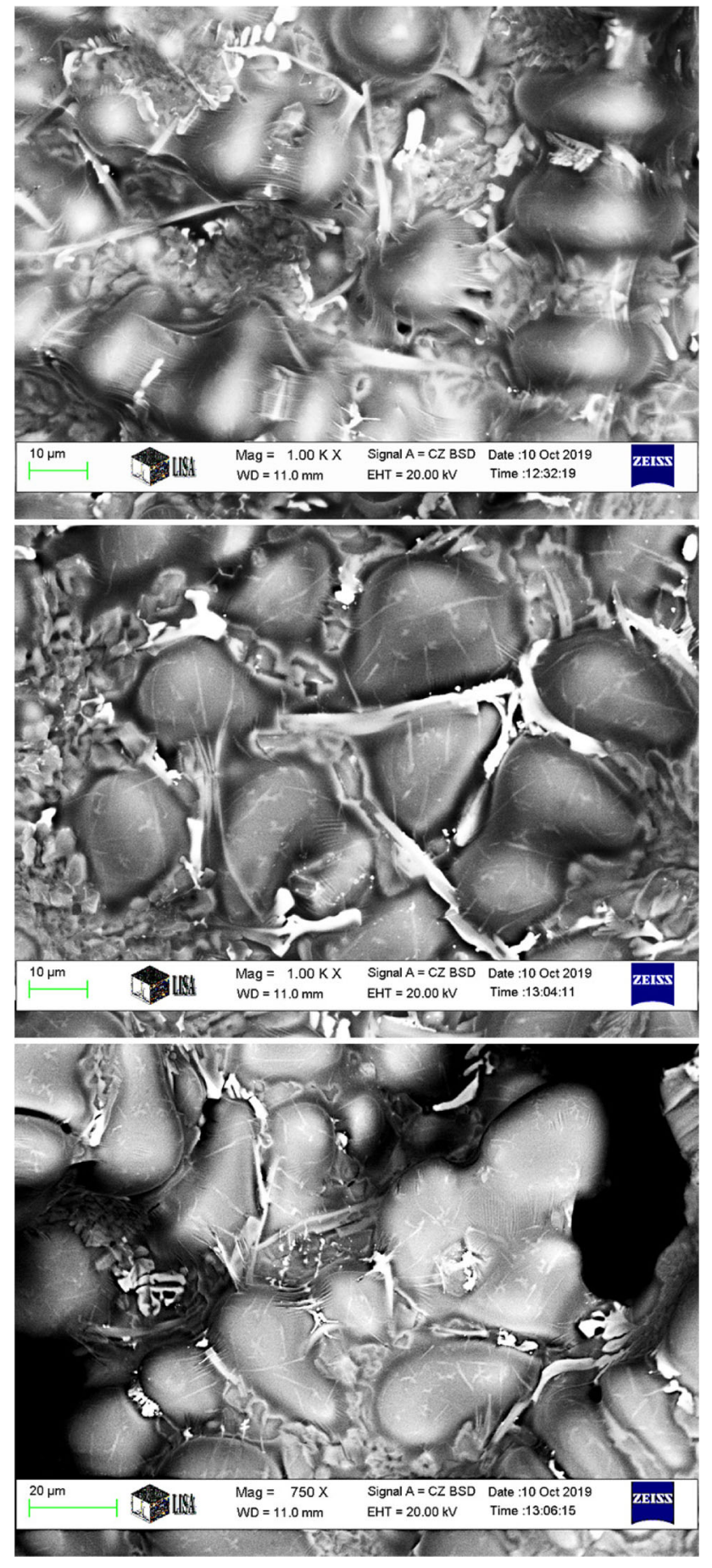

Figure 7. SEM images of thin, veil-like oxide films covering the dendritic network inside the pores found in the K-mold test pieces.

chemical reaction with the liquid metal to form $\mathrm{Al}_{2} \mathrm{O}_{3}$ and AlN. This suggests that the continuous nitridation of the inner surface of an $\mathrm{N}_{2}$ purging gas bubble can lead to the reduction in the volume of the bubble. Based on their experimental results, Raiszadeh and Griffiths ${ }^{58}$ determined the consumption rates of $\mathrm{O}_{2}$ and $\mathrm{N}_{2}$ in a bubble trapped in commercial purity liquid aluminum with a hydrogen

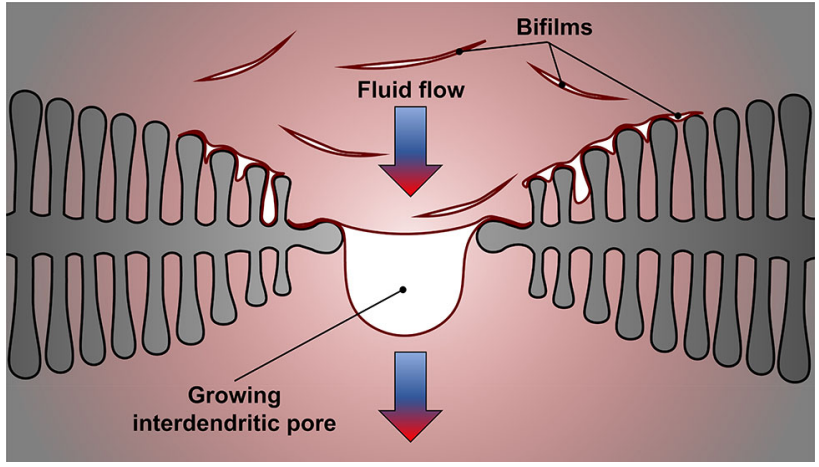

Figure 8. Schematic illustration of pore formation due to the flow restriction effect of bifilm defects.

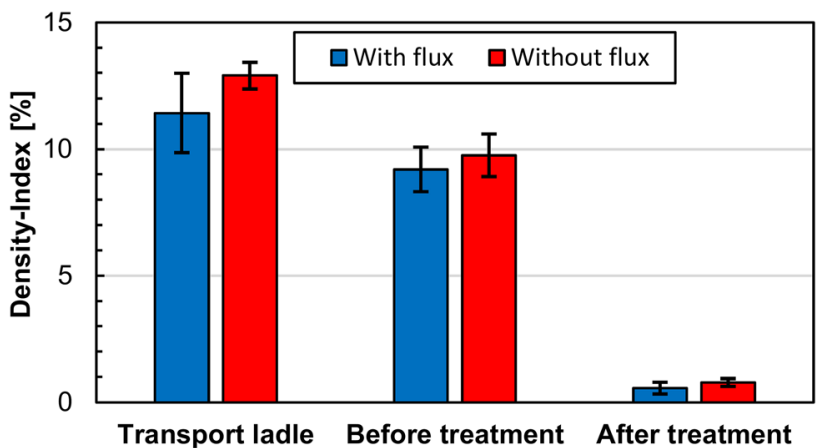

Figure 9. Average Density-Index values evaluated for samples cast at different melt preparation stages.

content of about $0.1 \mathrm{~mL} / 100 \mathrm{~g}$ at $700{ }^{\circ} \mathrm{C}$. The consumption rate of $\mathrm{N}_{2}$ can be given as:

$R_{N}=3.289 \times 10^{-6} f_{N}+2.058 \times 10^{-6}$

Eqn. 3

where $R_{N}$ is the consumption rate of $\mathrm{N}_{2}\left(\right.$ mole $\mathrm{s}^{-1} \mathrm{~m}^{-2}$ ) and $f_{N}$ is the mole fraction of $\mathrm{N}_{2}$ present in the atmosphere of the bubble. With the aid of $R_{N}$, the time needed for the consumption of the whole gas volume of an $\mathrm{N}_{2}$ bubble can be calculated as:

$t=\frac{n_{\mathrm{N}_{2}}}{A \cdot R_{N}}$

Eqn. 4

where $n_{\mathrm{N}_{2}}$ is the number of moles of $\mathrm{N}_{2}$ present in the bubble (mole), $A$ is the surface area of the bubble $\left(\mathrm{m}^{2}\right)$, and $t$ is the time needed for the consumption of all $\mathrm{N}_{2}$ molecules due to nitridation (s). If we assume that ideal gas law can be applied, the purging gas contains only $\mathrm{N}_{2}$ gas, and we neglect the metallostatic pressure, for a purging gas bubble with a diameter of $2 \mathrm{~mm}$ (as the usual size of bubbles created during rotary degassing is a few millimeters in diameter ${ }^{7,59,60}$ ), the time needed for the consumption of the inner atmosphere is approx. $13 \mathrm{~min}$. This value is rather close to the applied degassing time of $12 \mathrm{~min}$. In our case, however, the time required for the loss of inner gas atmosphere can somewhat differ from the calculated value, as the melt temperature and the composition were not the same as in Ref. 57, the diffusion of $\mathrm{H}$ into the bubbles was not taken into 

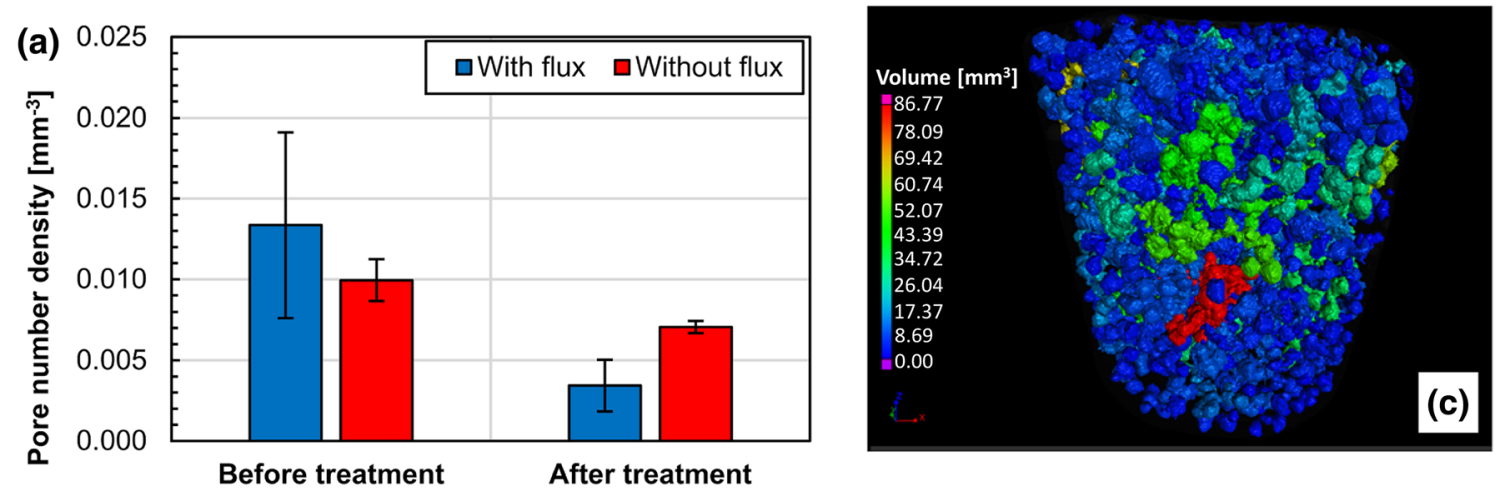

(b)
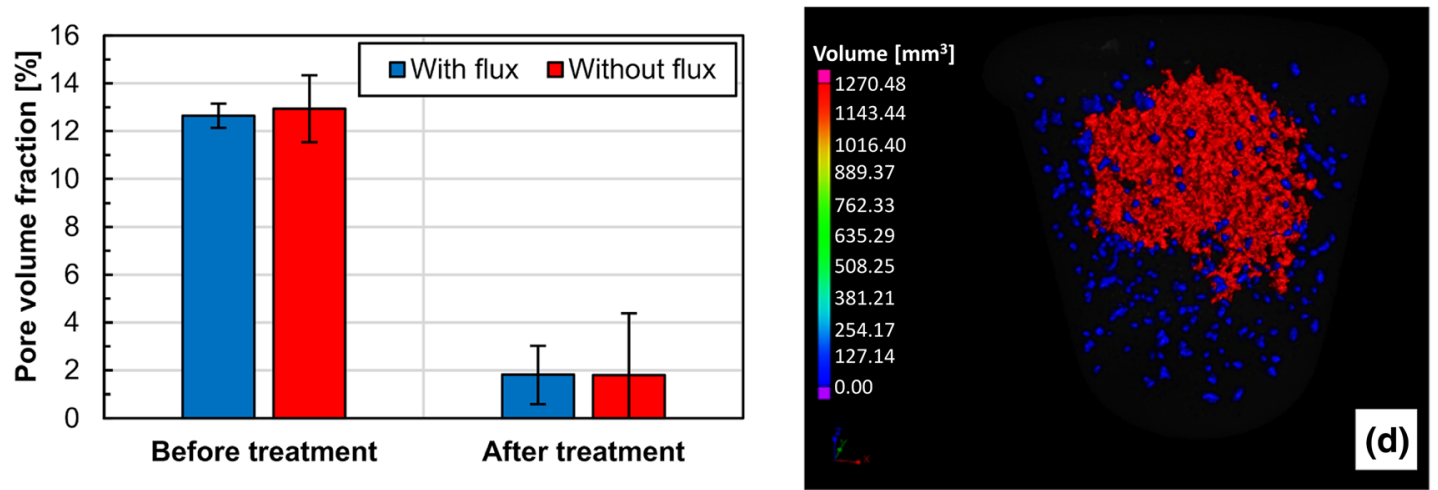

Figure 10. Results of the CT-analysis of RPT samples: average (a) pore number density and (b) pore volume fraction values. Representative reconstructed CT images of specimens cast (c) before and (d) following the melt treatments.

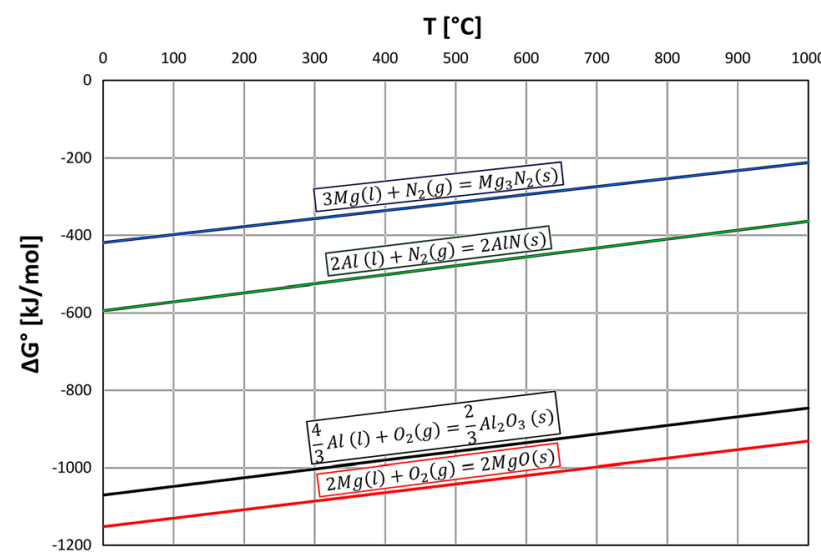

Figure 11. Gibbs free energy of formation of $\mathrm{Al}_{2} \mathrm{O}_{3}, \mathrm{AIN}$, $\mathrm{MgO}$, and $\mathrm{Mg}_{3} \mathrm{~N}_{2}$ (calculated per mole of $\mathrm{O}_{2}$ or $\mathrm{N}_{2}$ ) at different temperatures.

account, and the actual size of the bubbles is unknown. Despite these uncertainties, it is evident that a significant amount of $\mathrm{N}_{2}$ gas can be consumed during the degassing treatment, which leads to the reduction in the volume and thus, the buoyancy of the purging gas bubbles trapped under the dross layer. In this way, these bubbles with their AlN surface can stay in the upper region of the melt even after the melt treatment is finished and the dross layer is removed, as they do not have enough buoyancy to escape from the liquid metal. The described mechanism can explain the increment in the number of small-sized inclusions (nitride bifilms) due to the degassing treatments; however, more research work needs to be done in this field to fully understand the underlying phenomena and to improve the melt treatment methods used in the foundry industry based on the experimental results.

\section{Conclusion}

The present study was conducted to investigate the effects of rotary degassing treatments on the melt quality of an $\mathrm{Al}-$ $\mathrm{Si}-\mathrm{Mg}-\mathrm{Cu}$ casting alloy. Based on the results, the following conclusions can be drawn:

- Rotary degassing coupled with flux addition was an effective inclusion and solute hydrogen removal technique that could significantly improve melt quality.

- Without flux addition, melt treatments were only effective regarding degassing, while the inclusion content of the melts was significantly increased.

- Rotary degassing with $\mathrm{N}_{2}$ gas introduces numerous small-sized bifilm defects into the melts, which can be attributed to the chemical reaction between the $\mathrm{N}_{2}$ gas and the liquid alloy.

- Bifilms restrict interdendritic flow and initiate interdendritic pores, which indicate that the tendency to pore formation is highly dependent on the presence of these defects. 


\section{Acknowledgements}

Open access funding provided by University of Miskolc (ME). Supported by the UNKP-19-3 New National Excellence Program of the Hungarian Ministry for Innovation and Technology. The authors thank Professor John Campbell for the helpful discussion in connection with this work and Árpád Kovács for his assistance in the making of SEM images and EDS analysis.

Open Access This article is licensed under a Creative Commons Attribution 4.0 International License, which permits use, sharing, adaptation, distribution and reproduction in any medium or format, as long as you give appropriate credit to the original author(s) and the source, provide a link to the Creative Commons licence, and indicate if changes were made. The images or other third party material in this article are included in the article's Creative Commons licence, unless indicated otherwise in a credit line to the material. If material is not included in the article's Creative Commons licence and your intended use is not permitted by statutory regulation or exceeds the permitted use, you will need to obtain permission directly from the copyright holder. To view a copy of this licence, visit http://creativecommons. org/licenses/by/4.0/.

\section{REFERENCES}

1. S. Shivkumar, L. Wang, D. Apelian, JOM 43, 26-32 (1991). https://doi.org/10.1007/BF03220114

2. A.M. Samuel, F.H. Samuel, J. Mater. Sci. 27, 6533-6563 (1992). https://doi.org/10.1007/ BF01165936

3. F. Czerwinski, Metall. Mater. Trans. B 48, 367-393 (2017). https://doi.org/10.1007/s11663-016-0807-6

4. P.K. Trojan, R. Fruehan, Inclusion-Forming Reactions. in ASM Handbook, Volume 15: Casting, 74-83 (ASM International, 2008). https://doi.org/10.1361/ asmhba0005193

5. R. Gallo, AFS Trans. 125, 97-110 (2017)

6. A.M. Samuel, H.W. Doty, S. Valtierra, F.H. Samuel, Int. J. Met. 12, 625-642 (2018). https://doi.org/10. 1007/s40962-017-0185-0

7. J. Campbell, Complete Casting Handbook, $2^{\text {nd }}$ edn. (Elsevier Ltd. Oxford, 2015) 3-90, 341-415, 779-783

8. G. Gyarmati, G. Fegyverneki, T. Mende, M. Tokár, Mater. Charact. 157, 109925 (2019). https://doi.org/ 10.1016/j.matchar.2019.109925

9. J. Campbell, Metall. Mater. Trans. B 37, 857-863 (2006). https://doi.org/10.1007/BF02735006

10. J. Campbell, J. Mater. Sci. Technol. 22, 127-145 (2006). https://doi.org/10.1179/174328406X74248

11. J. Campbell, Metall. Mater. Trans. B 42, 1091-1097 (2011). https://doi.org/10.1007/s11663-011-9575-5

12. J. Campbell, Stop pouring, start casting. Int. J. Met. 6, 7-18 (2012)

13. D. Dispinar, J. Campbell, Mater. Sci. Eng. A 528, 3860-3865 (2011). https://doi.org/10.1016/j.msea. 2011.01.084
14. Q.G. Wang, C.J. Davidson, J.R. Griffiths, P.N. Crepeau, Metall. Mater. Trans. B 37, 887-895 (2006). https://doi.org/10.1007/BF02735010

15. F. Chiesa, D. Levasseur, G. Morin, B. Duchesne, Int. J. Met. 10, 216-223 (2016). https://doi.org/10.1007/ s40962-016-0029-3

16. X.B. Cao et al., Int. J. Cast Met. Res. 27, 362-368 (2014). https://doi.org/10.1179/1743133614Y. 0000000120

17. M. Uludag, M. Uyaner, F. Yilmaz, D. Dispinar, Arch. Foundry Eng. 15, 134-140 (2015). https://doi.org/10. 1515/afe-2015-0093

18. X.Y. Zhao et al., Acta Metall. Sin. (English Lett.) 30, 541-549 (2017). https://doi.org/10.1007/s40195-0160526-7

19. M.A. El-Sayed, W.D. Griffiths, Int. J. Cast Met. Res. 27, 282-287 (2014). https://doi.org/10.1179/ 1743133614Y.0000000113

20. C. Yuksel et al., Arch. Foundry Eng. 16, 151-156 (2016)

21. E. Erzi, Ö. Gürsoy, C. Yüksel, M. Colak, D. Dispinar, Metals 9, 957 (2019). https://doi.org/10.3390/ met9090957

22. D. Dispinar, J. Campbell, Int. J. Cast Met. Res. 17, 280-286 (2004). https://doi.org/10.1179/ 136404604225020696

23. P. Yousefian, M. Tiryakioğlu, Metall. Mater. Trans. A 49, 563-575 (2018). https://doi.org/10.1007/s11661017-4438-6

24. Tiryakioğlu, M. The Myth of Hydrogen Pores in Aluminum Castings. in Shape Casting (eds. Tiryakioğlu, M., Griffiths, W. \& Jolly, M.) 143-150 (TMS, 2019). https://doi.org/10.1007/978-3-030-06034-3_14

25. W.D. Griffiths, R. Raiszadeh, J. Mater. Sci. 44, 3402-3407 (2009). https://doi.org/10.1007/s10853009-3450-7

26. B. Farhoodi, R. Raiszadeh, M.H. Ghanaatian, J. Mater. Sci. Technol. 30, 154-162 (2014). https://doi. org/10.1016/j.jmst.2013.09.001

27. J.R. Brown, Foseco Non-Ferrous Foundryman's Handbook, 11th edn. (Foseco International Ltd., Oxford, 1999), pp. 72-76

28. D.V. Neff, Degassing. in ASM Handbook Volume 15: Casting (ASM International, 2008), pp. 185-193. https://doi.org/10.1361/asmhba0005353

29. A. Pascual, China Foundry 6, 358-365 (2009)

30. X. Cao, J. Campbell, in 2nd International Aluminum Casting Technology Symposium, pp. 135-146 (2002)

31. G.K. Sigworth, AFS Trans. 95, 73-78 (1987)

32. M. Mostafaei, M. Ghobadi, G.B. Eisaabadi, M. Uludağ, M. Tiryakioğlu, Metall. Mater. Trans. B 47, 3469-3475 (2016). https://doi.org/10.1007/s11663016-0786-7

33. E. Lordan, J. Lazaro-Nebreda, Y. Zhang, Z. Fan, JOM 71, 824-830 (2019). https://doi.org/10.1007/s11837018-3186-4 
34. T. Yamamoto, W. Kato, S.V. Komarov, Metall. Mater. Trans. B (2019). https://doi.org/10.1007/ s11663-019-01681-2

35. C. Lee, T. So, K. Shin, Acta Metall. Sin. (English Lett.) 29, 638-646 (2016). https://doi.org/10.1007/ s40195-016-0434-X

36. V.S. Warke, G. Tryggvason, M.M. Makhlouf, J. Mater. Process. Technol. 168, 112-118 (2005). https:// doi.org/10.1016/j.jmatprotec.2004.10.017

37. B. Wan, W. Chen, M. Mao, Z. Fu, D. Zhu, J. Mater. Process. Technol. 251, 330-342 (2018). https://doi. org/10.1016/j.jmatprotec.2017.09.001

38. M. Hernández-Hernández, W. Cruz-Mendez, C. González-Rivera, M.A. Ramírez-Argáez, Mater. Manuf. Process. 30, 216-221 (2015). https://doi.org/ 10.1080/10426914.2014.952303

39. R. Gallo, AFS Trans. 116, 195-220 (2008)

40. D. Dispinar, S. Akhtar, A. Nordmark, M. Di Sabatino, L. Arnberg, Mater. Sci. Eng. A 527, 3719-3725 (2010). https://doi.org/10.1016/j.msea.2010.01.088

41. H. Ni, B. Sun, H. Jiang, W. Ding, Mater. Sci. Eng. A 352, 294-299 (2003). https://doi.org/10.1016/S09215093(02)00900-0

42. J. Campbell, Concise Castings (American Foundry Society, Schaumburg, 2010), p. 39

43. K. Strauss, Applied Science in the Casting of Metals (Pergamon Press Ltd., Oxford, 1970), p. 265

44. C. Borgonovo, D. Apelian, M.M. Makhlouf, JOM 63, 57-64 (2011). https://doi.org/10.1007/s11837-0110030-5

45. C. Borgonovo, M.M. Makhlouf, Metall. Mater. Trans. 47, 5125-5135 (2016). https://doi.org/10.1007/ s11661-016-3665-6

46. C. Borgonovo, M.M. Makhlouf, Metall. Mater. Trans. A 47, 1818-1827 (2016). https://doi.org/10.1007/ s11661-016-3328-7

47. S.W. Hudson, D. Apelian, Int. J. Met. 10, 315-321 (2016). https://doi.org/10.1007/s40962-016-0030-X
48. M.B. Djurdjevic, Z. Odanovic, J. Pavlovic-Krstic, Metall. Mater. Eng. 16, 63-76 (2010)

49. M. Uludağ, R. Çetin, D. Dispinar, M. Tiryakioğlu, Int. J. Met. 12, 853-860 (2018). https://doi.org/10.1007/ s40962-018-0217-4

50. D. Dispinar, J. Campbell, Int. J. Cast Met. Res. 19, 5-17 (2006). https://doi.org/10.1179/ 136404606225023300

51. S. Fox, J. Campbell, Int. J. Cast Met. Res. 14, 335-340 (2002). https://doi.org/10.1080/13640461.2002. 11819451

52. S. Fox, J. Campbell, Scr. Mater. 43, 881-886 (2000). https://doi.org/10.1016/S1359-6462(00)00506-6

53. X. Cao, J. Campbell, Can. Metall. Q. 44, 435-448 (2005). https://doi.org/10.1179/cmq.2005.44.4.435

54. J. Campbell, M. Tiryakioğlu, Sci. Technol. 26, 262-268 (2010). https://doi.org/10.1179/ 174328409X425227

55. NIST Standard Reference Database Number 69, https://doi.org/10.18434/t4d303

56. L.C.B. Martin, C.T. Keller, S. Shivkumar, in AFS 3rd International Conference on Molten Aluminum Processing, pp. 79-91, Orlando: Florida, 1992

57. R. Raiszadeh, W.D. Griffiths, Metall. Mater. Trans. B 37, 865-871 (2006). https://doi.org/10.1007/ BF02735007

58. R. Raiszadeh, W.D. Griffiths, Metall. Mater. Trans. B 39, 298-303 (2008). https://doi.org/10.1007/s11663008-9142-x

59. A.G. Szekely, Metall. Trans. B 7, 259-270 (1976). https://doi.org/10.1007/BF02654925

60. D.O. Tovio, G.W. Mugica, A.C. González, J.C. Cuyas, AFS Trans. 108, 457-462 (2000)

Publisher's Note Springer Nature remains neutral with regard to jurisdictional claims in published maps and institutional affiliations. 